\title{
Creutzfeldt-Jakob verdict may prompt new claims
}

London. In what may be only the first in a succession of similar cases, a verdict of "medical misadventure" was reached last week in Lincoln following an inquest into the case of a young man who died of Creutzfeldt-Jakob disease (CJD), contracted as a result of treatment with contaminated human growth hormone.

CJD is a neurodegenerative disease characterized by rapidly developing dementia; death follows often less than a year after onset. It is related to bovine spongiform encephalopathy (BSE), better known as ' $\mathrm{mad}$ cow disease', and the sheep illness scrapie.

Although familial clusters of inherited CJD exist, overall incidence in the general population is approximately 1 in 10,000 individuals, with an average age of onset of 61 years. For this reason, the deaths of three young adults from CJD reported in early 1985 in the United States were suspicious.

The three were among 7,000 people who had been treated with pituitary growth hormone derived from cadavers, a practice carried out in many countries to treat growth deficiencies. Such use of the hormone was suspended in the United States, and the United Kingdom followed in May the same year, after a confirmed case of CJD. Both countries authorized use of recombinant human growth hormone later that year.

CJD can be transmitted by infection with particles containing an abnormal form of the prion protein (see Nature 365, 386;1993). The brains of CJD-infected cadavers contain these infectious particles, which are highly resistant to most common sterilization procedures.

Cadavers of affected individuals not diagnosed for CJD could contain prion particles without the brain having the spongiform appearance typical of late CJD. As preparation of one batch of hormone required up to 20,000 pituitary glands, it was not unlikely that a batch could have become contaminated.

The case considered by the inquest jury is certainly not isolated, as ten of the 1,900 patients treated with growth hormone in Britain between 1958 and 1985 have already died. Families of those treated with growth hormone have asked the British government to agree to pay compensation similar to that given to haemophiliacs infected with HIV by contaminated blood products. But the government is denying liability, on the grounds that precautions were taken as soon as the risk became evident.

The problem of contaminated growth hormone is not limited to Britain. Legal procedures have been opened against two French doctors, charging them with "involuntary homicide" in supplying contaminated hormone (see Nature 364, 372; 1993). Cadaver-derived hormone was used in France until the end of 1988 , when the recombinant product was introduced.

The French government has now announced that, whether or not any negligence was involved, it is prepared to assume full responsibility, and that people with $\mathrm{CJD}$ will be compensated. Legal procedures already under way will not be interrupted. But legal action against those responsible for possible malpractice is a separate issue from compensation for the victims.

There is still a large number of people worldwide who were treated with possibly contaminated products but who have not developed CJD. The incubation period can be up to 40 years, but as recent studies indicate that there is a genetic predisposition for iatrogenic CJD, owing to contaminated growth hormone or contaminated dura mater used in brain surgery, it may be possible to identify those at greater risk

Meanwhile, the question of who is responsible when such contaminations occur rages on in both Italy and Germany (see right) where scandals over contaminated blood are just breaking. Kimberly Carr

If Paracelsus had been born in 1993 instead of 1493, his leanings towards mysticism could have lead him to a life in modern Europe's alternative circles. But Paracelsus - born Philippus Aureolus Theophrastus Bombastus von Hohenheim - was even more of a thorn in the flesh of the establishment, challenging accepted medical views to the point of publicly burning medical textbooks while teaching at the University of Basel.

He was forced to flee academia in 1528 under threat of arrest, and spent the rest of his life wandering among the peasants of central Europe. Responsible for more than 200 publications covering aspects as diverse as folk medicine, alchemy and cosmology, Paracelsus is now widely considered the founder of medical chemistry. Five hundred years after his birth in Einsiedeln Switzerland, a celebratory stamp was issued in Germany this week to pay homage to this scientific debt. Last year he was rehabilitated by the Pope.

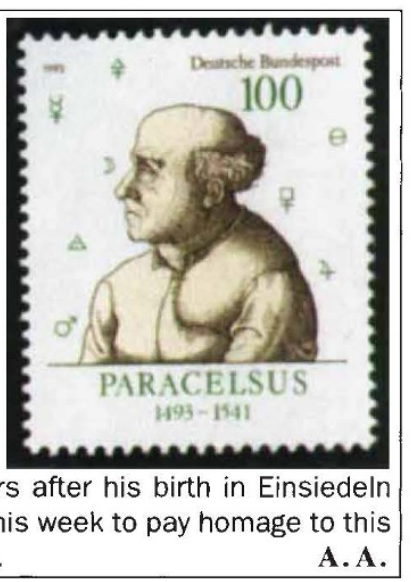

\section{Concern grows over impact of German blood scandal}

Munich. The German AIDS scare, which began with the closure of the pharmaceutical blood product company UB Plasma in Koblenz, developed this week into a nationwide panic after Horst Seehofer, the health minister, recommended on 3 November that anyone who received blood or blood products since the early 1980s should undergo an HIV test.

UB Plasma was accused two weeks ago of failing to screen all its blood products for HIV contamination. Four employees have so far been arrested. Products have been distributed widely throughout Germany and other European countries. In addition, 500 litres of untested blood from Romania, delivered to UB Plasma but stored at its Vienna-based partner company, Octaplasma, have disappeared; it is not known if the blood has been sold to hospitals.

Seehofer has been criticized for creating a panic that has caused thousands of individuals to back out of both routine and in some cases urgent surgery. Doctors have warned that refusing treatment can present a higher risk to patients than that of receiving infected blood products, and that Germany may lack the capacity to carry out all the tests likely to be demanded.

So far, only three cases of AIDS infection have been associated with UB Plasma products. But more could appear. The regional state government of Rhineland-Pfalz is to test samples from each of the UB Plasma's blood donors, of which there are estimated to be about 25,000 , in order to pinpoint the exact source of infection.

Seehofer is disbanding the federal health bureau which, he said, had been careless about reporting cases of AIDS infection which had been caused by blood transfusion (see Nature 365, 687; 1993). But carelessness may have been even more pervasive. The news magazine Der Spiegel this week reported that the district council of Koblenz had been told of suspicions about UB Plasma's practices as long ago as 1987 , but had filed the report without acting on it. Last week, the director of pharmaceutics in the district council, Gerhard Frick, was relieved of his duties relating to control of blood and blood products.

Der Spiegel believes that a much wider conspiracy exists; it also reports that a consultant at the Bonn University Clinic, the biggest haemophiliac centre in the world, has had more than DM2 million transferred into a numbered Swiss bank account.

Officials at federal and local levels are trying hard to contain the crisis, recalling UB Plamsa products, choosing safe replacements for them and offering free, anonymous AIDS testing.
Alison Abbott 